\title{
POPULAÇÃO, TURISMO E URBANIZAÇÃO: CONFLITOS DE USO E GESTÃO AMBIENTAL
}

\author{
HELOISA SOARES DE MOURA COSTA ${ }^{1}$ \\ Universidade Federal de Minas Gerais \\ ALEXANDRE MAGNO DE OLIVEIRA ${ }^{2}$ \\ MARCELO VIANA RAMOS ${ }^{3}$
}

\section{Introdução}

O trabalho tem por objetivo discutir alguns dos conflitos sócio-ambientais gerados em regiões em acelerado processo de transformação em decorrência da intensificação de atividades ligadas ao turismo. A discussão busca, por um lado, enfocar os impactos de tais transformações sobre grupos populacionais específicos, como as populações tradicionais residentes e os migrantes atraídos pelas novas atividades, procurando compreender as estratégias de resistência e/ou de inserção desenvolvidas frente ao novo. Por outro lado, explora a natureza de tais transformações, em grande parte materializada num acelerado processo de urbanização que, ao associar atividade imobiliária com intenso consumo de recursos naturais e cênicos, homogeneiza as relações de produção e consumo. Trata-se, assim de uma conflituosa

\footnotetext{
'Professora do Programa de Pós-Graduação em Geografia - IGC/UFMG. O presente trabalho é parte dos resultados da pesquisa "Tendências recentes de produção do meio ambiente urbano: Planejanento, conflito e gestão urbano-ambiental", realizada com o apoio do CNPq (Bolsa de Produtividade em Pesquisa) e da FAPEMIG.

${ }_{3}^{2}$ Geógrafo, Mestre em Geografia (IGC/UFMG)

${ }^{3}$ Professor Assistente da UFOP, Mestre em Geografia (IGC/UFMG)
} 
busca de equilíbrio entre necessidades de preservação cultural e ambiental e construção de alternativas econômicas de base local. A garantia da integridade do patrimônio ambiental da região, simultaneamente valor de uso e valor de troca, constantemente ameaçada pela atividade , é também uma necessidade para a sobrevivência econômica da mesma.

Para tanto, serão utilizados dois casos aparentemente opostos, porém que, conforme argumentaremos ao longo do trabalho, são presididos pela mesma lógica de produção e apropriação do espaço: as áreas tradicionalmente ligada ao eco-turismo institucionalmente protegidas pela criação de parques e APAs - Áreas de Proteção Ambiental - e a região costeira e sua crescente urbanização ligada ao turismo, particularmente o turismo de massa. Os exemplos emblemáticos são respectivamente a região do PARNA Serra do Cipó em Minas Gerais e o litoral sul da Bahia.

\section{População, conflitos sócio-ambientais e transformações espaciais}

Os casos aqui apresentados integram uma pesquisa, de caráter eminentemente exploratório, de identificação de casos que contribuíssem para o avanço da compreensão das relações entre população e meio ambiente, por meio de duas linhas centrais: a análise de experiências contemporâneas de planejamento e gestão urbana e ambiental que incorporem simultaneamente preocupações sociais e ambientais; e a análise de situações de conflito urbano-ambiental, materializados ou não em movimentos sociais e/ou lutas ambientais ${ }^{4}$. No presente trabalho explora-se principalmente a segunda linha mencionada, embora seja importante uma breve referência à pesquisa em seu conjunto (COSTA, 2001).

Dentre as tendências contemporâneas de planejamento e gestão urbana e ambiental, pode-se destacar a preocupação generalizada com a criação de formas mais democráticas de gestão, seja pela adoção de metodologias e práticas participativas, seja pela criação de instâncias colegiadas e multisetoriais de gestão de políticas. Outra tendência bastante presente tem sido a adoção de recortes espaciais determinados, eles próprios fruto de um planejamento anterior, dentro dos quais vigoram regulações específicas urbanísticas, ambientais ou de gestão. As Áreas de Proteção Ambiental (APAs), bacias hidrográficas, as Zonas de Especial Interesse Urbanístico (ZEIS), os Zoneamentos Econômico-Ecológicos (ZEEs), são alguns exemplos. Em várias situ-

\footnotetext{
${ }^{4}$ Para uma discussão sobre movimentos sociais, ver por exemplo Kowarick (2000), que faz uma distinção interessante entre conflito, luta e movimento social. Oliveira (2001) apresenta uma concisa mas objetiva discussão sobre a transformação de conflitos ambientais em lutas ambientais. À luz da distinção proposta, que teoricamente se baseia na constituição e reconhecimento dos grupos e atores enquanto sujeitos sociais (cf. BOURDIEU) os casos aqui analisados certamente caracterizariam conflitos ambientais, explícitos ou latentes, mas ainda não necessariamente lutas ambientais, embora muitas vezes com potencial para tanto.
} 
ações as duas tendências aparecem associadas entre si, como os Comitês Gestores de APAs ou de bacias. Além disto, muitas vezes tais instâncias de gestão assumem importantes papéis de mediadores de conflitos que se manifestam na esfera urbanoambiental.

Os casos selecionados referem-se a áreas em conflito de uso, onde confrontam-se metas econômicas, sociais e ambientais. Tal conflito pode ser explícito, como se verá no caso do turismo de natureza da Serra do Cipó, ou implícito, como no caso dos interesses divergentes entre o turismo empresarial do litoral brasileiro e as necessidades de preservação ambiental, até mesmo, embora não somente, para garantir as condições de continuidade da atividade, além de assegurar as condições adequadas de vida e trabalho para a população. Ambas as áreas encontram-se sob impacto de novas atividades econômicas, onde há grande pressão ambiental e sócio-cultural das novas atividades associadas ao turismo ecológico e de natureza, logo em constante transformação demográfica e espacial.

A identificação e discussão de conflitos urbano-ambientais ou sócio-ambientais vem se caracterizando como uma promissora área de investigação, na medida em que possibilita compreender mais claramente as diferentes lógicas que articulam interesses que se contrapõem em situações concretas. Em algumas situações pode-se identificar uma total assimetria entre os grupos e/ou agentes envolvidos, em outros casos há possibilidades de mediações.

Trabalhou-se com a hipótese segundo a qual o estabelecimento de zoneamentos especiais, associados a mecanismos de regulação e gestão democrática nas/das mesmas, vem constituindo uma das mediações possíveis entre interesses em conflito. A criação das APAs - Áreas de Proteção Ambiental - como o próprio nome indica, traz consigo a intenção de um mínimo de controle do processo de ocupação com vistas à proteção do patrimônio natural. A intensificação da urbanização nestas áreas, pressupõe, portanto, o diálogo entre os interesses associados à produção do ambiente construído e a transformação/manutenção das características dos espaços naturais. Concebida no bojo da legislação ambiental contemporânea, a gestão destas unidades deverá estar associada a um órgão colegiado, um conselho, representativo das populações, instituições e agentes econômicos que atuam na área. Como poucos conselhos gestores de APAs foram, de fato, até agora implementados, estamos numa fase intermediária, na qual os mecanismos de regulação estão estabelecidos para territórios já delimitados, mas ainda sem muita efetividade na gestão dos conflitos.

Por outro lado, áreas sob o impacto de novas atividades econômicas, logo em intenso processo de transformação, são via de regra palco de inúmeros conflitos de interesses. A implantação de atividades ligadas ao turismo, constitui um excelente caso para reflexão, uma vez que tal atividade depende, simultaneamente de duas forças contrárias: da manutenção e da exploração de elementos da natureza. Os casos apresentados possibilitam interessantes comparações, já que referem-se a processo distintos de impacto motivado pela atividade turística, bem como de possibilidades diferenciadas de gestão. 


\section{Primeiro caso: preservação ambiental e urbanização numa área de turismo de natureza: a Serra do Cipó em Minas Gerais ${ }^{5}$.}

O foco é o processo de urbanização em duas Unidades de Conservação (UC) em Minas Gerais, na região da Serra do Cipó (distrito de Cardeal Mota). Essas unidades, a Área de Proteção Ambiental Morro da Pedreira e o Parque Nacional da Serra do Cipó, localizam-se na Serra do Espinhaço, com acesso principal pela MG-10, a cerca de $100 \mathrm{~km}$ de Belo Horizonte. A região vem experimentando um intenso processo de transformação em função do crescimento do ecoturismo e da crescente expansão imobiliária, associada à fuga, para segundas residências e sítios de recreio, de parcela da população metropolitana. Na região, há conflitos associados tanto a interesses divergentes em termos de uso do espaço, quanto a diferenças entre modos de vida mais tradicionais e outros que compõem um enorme espectro, mais típicos das grandes áreas urbanas, aí incluindo-se tanto os turistas/ecologistas/pesquisadores, quarnto os praticantes de um turismo de massa .

Além do estudo de alguns elementos básicos da dinâmica urbano-ambiental na região, foram identificados de três tipos interessantes de conflitos:

a) conflitos fundiários em torno da criação do parque, visto pela população tradicional como uma invasão de seus direitos, visto pelos ecologistas e por parte desta mesma comunidade como uma garantia de preservação de um importante patrimônio coletivo, ao mesmo tempo que é um indutor de um determinado tipo de turismo, o ecoturismo, que se quer manter e incentivar, com um mínimo de controle.

b) conflitos em torno de obras de pavimentação da MG-10, que corta e estrutura a localidade, gerando ampla mobilização da comunidade e várias entidades e instituições, que culminou em recente audiência pública para discussão da questão.

c) conflitos mais abrangentes e difusos em torno do recente processo de urbanização dentro da APA, caracterizado principalmente por loteamentos para recreio e expansão urbana

O distrito de Cardeal Mota localiza-se entre os rios Cipó e Parauninha, local onde dois vetores históricos da região se interceptam: o Rio Cipó e a estrada para Conceição do Mato Dentro. Seu relevo bastante movimentado é incrustado de pedras, fragmentado, cortado por diversas cachoeiras, quase sempre inacessíveis para a maioria da população, pouca vegetação lenhosa e solo ralo, não propício para formação de grandes lavouras, excetuando-se alguns vales. Apesar de explorado desde o século XVII, somente a partir dos anos 70 a região começa a passar por transformações significativas, impulsionadas em grande medida pelo turismo ecológico. Conflitos de uso surgem e se acentuam em virtude do crescente afluxo de pessoas que querem conhecer a região, passear, acampar, tomar banho de cachoeira, comprando sítios e chácaras, oferecidos por um número também crescente de empreendimentos imobiliários, caracterizados por segundas residências e sítios de recreio. A partir do início

\footnotetext{
${ }^{5}$ Ver Oliveira (2002), para uma discussão mais aprofundada deste caso.
} 
da década de 80 é criado na região o Parque Nacional da Serra do Cipó - PARNA CIPÓ $^{6}$ e logo a seguir a APA Morro da Pedreira, sendo então a única unidade de conservação federal que tem uma Área de Proteção Ambiental em seu entorno.

Durante um longo período, o discurso ambiental alimentou o mito da natureza intocada pelo homem como alternativa única de preservá-la. Nesta perspectiva toda “intervenção" do homem no meio físico certamente provoca um impacto ambiental . Esta posição fragmenta as opiniões, coloca numa extremidade o homem e em outra o meio físico (geralmente considerado como natureza). Neste contexto, qual seria a relação entre a urbanização e as áreas protegidas? O processo urbano contemporâneo ocorre em todas as direções, aproximando todos os espaços, ao mesmo tempo em que é segregador. Nem mesmo as "áreas protegidas", as Unidades de Conservação estão excluídas, pelo contrário, é por causa dos conflitos excludentes, intrínsecos do processo de acumulação capitalista, que elas são instituídas.

No território mineiro, especialmente em Santana do Riacho, no distrito de Cardeal Mota, encontram-se explicitamente essas evidências empíricas no entorno das "áreas protegidas" da Serra do Cipó. Apesar de um certo pioneirismo em Minas Gerais no tocante à normalização do processo de gestão ambiental no cenário nacional, evidenciado pela publicação da Lei Proteção e Conservação e Melhoria do Meio Ambiente (Lei Estadual 7.772/80) antes mesmo da Lei de Política Nacional do Meio Ambiente (Lei Federal 6.938/81), ainda assim são muitas as dificuldades quando a questão é gerenciar "áreas protegidas", devido à existência de diversos propósitos para o mesmo local.

A Serra do Cipó $^{8}$ integra o complexo serrano do Espinhaço e serve como limite territorial de muitas localidades, entre elas o município de Santana do Riacho e seu único distrito de Cardeal Mota. Apesar da proximidade de Belo Horizonte (FIG. 1),

\footnotetext{
"Foi criado pelo decreto estadual $\mathrm{n}^{\circ} 19.278$ de 03 de julho de 1977 , passando para a jurisdição federal pelo decreto federal $\mathrm{n}^{\circ} 90.223$ de 25 de setembro de 1984. Possui superfície de 31.010 hectares e está assentado nos territórios de quatro municípios de Minas Gerais: Itambé do Mato Dentro, Jaboticatubas, Morro do Pilar e Santana do Riacho. Já a APA Morro da Pedreira, além dos municípios já citados, abrange também Conceição do Mato Dentro, Itabira, Nova União e Taquaraçu de Minas. A APA foi instituída pelo decreto federal nº 98.891 de 26 de janeiro de 1990, possui área de 99.362 hectares, sendo que em muitos locais abrange inclusive áreas urbanas (CAMARGOS, 1999). Em sua área também está inserido outro tipo de Unidade de Conservação, a Reserva Particular de Patrimônio Natural - RPPN - Reserva da Cachoeira, totalizando uma área de 72 hectares. Sob jurisdição federal, foi instituída pela Portaria 39 do IBAMA, de 30 de abril de 1997 e é propriedade da ZAREIA Empreendimentos Ltda, (CAMARGOS, 2001).

$\mathrm{O}$ ordenamento jurídico brasileiro considera impacto ambiental como qualquer alteração das propriedades físicas, químicas ou biológicas do meio ambiente, causada por qualquer forma de matéria ou energia resultante das atividades humanas que, direta ou indiretamente, afetam: i) a saúde, a segurança e o bem estar da popula(̧ão; ii) as atividades sociais e econômicas; iii) a biota; iv) as condições estéticas e sanitárias do meio ambiente; v) a qualidade dos recursos ambientais (Art $1^{\circ}$ da Resolução 01/86 do Conselho Nacional de Meio Ambiente - CONAMA). A intenção do legislador é mensurar a degradação ambiental a partir dos resultados materiais que o meio físico "sofre" com a intervenção humana.

${ }_{8}^{8}$ Muitos moradores da região atribuem essa toponímia à forma do rio, sinuosa, como sugere a estrutura da planta. Outros atestam que é devido à quantidade de espécimes de cipó que os tropeiros encontravam, quando iam atravessar o rio. O mais importante não é desvendar a questão, mas destacar o nome - Cipó - no imaginário das pessoas, como sinônimo de ambiente saudável.
} 
este distrito tem uma população residente pouco numerosa (1.533 habitantes em 2000). Entretanto, nos feriados prolongados como Semana Santa ou Carnaval, a população visitante alcança 40.000 habitantes, segundo dados do IBAMA. Nesta região os conflitos ambientais concentram-se na unidade de conservação de uso direto ${ }^{9}$, pois essa categoria de manejo permite a intervenção direta do homem e a fiscalização concentra-se, principalmente, na unidade de conservação de uso indireto, dentro do Parque Nacional.

\section{FIGURA 1 - CROQUI DE LOCALIZAÇÃO DO PARNA SERRA DO CIPÓ NA APA MORRO DA PEDREIRA}

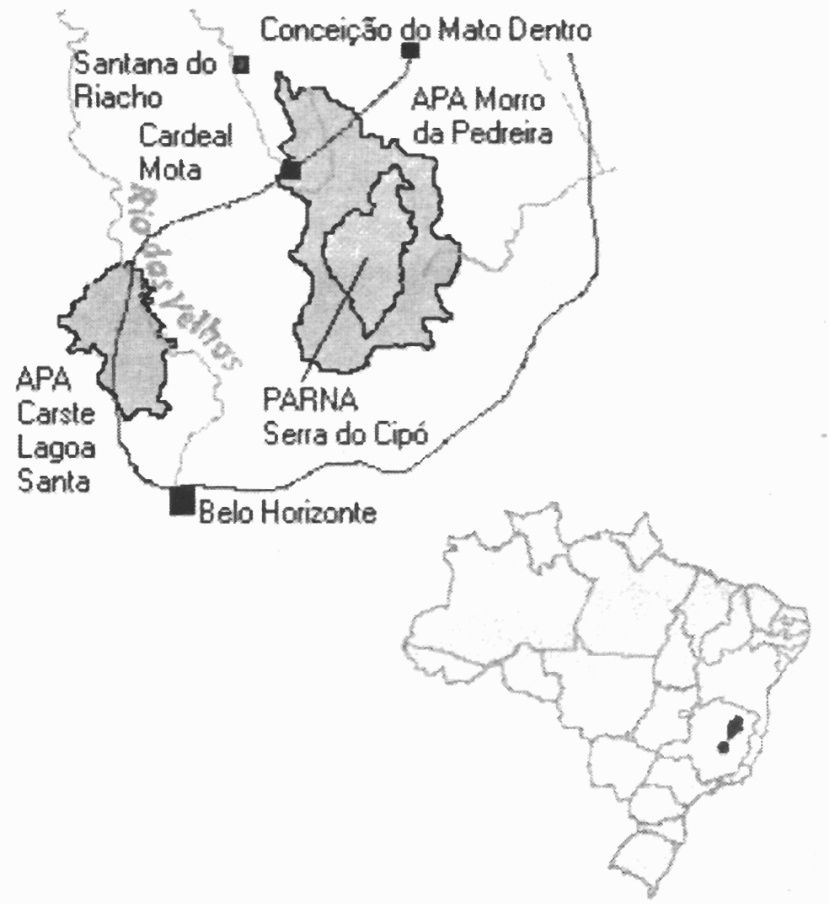

FONTE: Croqui desenvolvido a partir do site do IBAMA http://www.ibama.gov.br. Escala original 1:2.000.000 Base Cartográfica 1:2.500.000. Elaborado em 16/06/2000.

\footnotetext{
${ }^{9}$ As unidades de conservação podem ser classificadas quanto ao uso: i) direto, quando é permitido ao homem apropriar-se diretamente dos bens ambientais - minerais, vegetais, animais, solo, etc., como ocorre numa Área de Proteção Ambiental - APA ou Área de Relevante Interesse Ecológico - ARIE, Reservas Extrativistas - RESEX; ii) indireto, quando o acesso aos bens ambientais ocorrer de forma imediata, como a relação de uma floresta com o homem para que ela realize as trocas gasosas, ou para perpetuar a biodiversidade, manter o equilíbrio hídrico de uma micro-bacia hidrográfica, etc. Este uso ocorre nos Parques, Reservas Ecológicas, Reservas Biológicas, Estações Ecológicas, sendo mais difícil de ser abstraído, principalmente na propriedade privada, onde geralmente a pessoa que tem a posse não aceita que outros a acessem, mesmo de maneira indireta, embora este bem esteja tutelado pelos interesses difusos da sociedade com o propósito de manter o ambiente sustentável.
} 
Os problemas urbanos e sócio-ambientais, são inúmeros na área : a questão fundiária associada à especulação imobiliária; o lixo gerado e dissipado pelo local sem passar por beneficiamento seletivo antes da destinação final; a deficiência de uma rede de esgoto com tratamento dos efluentes líquidos; a carência de fiscalização pública para acompanhar as hospedarias e áreas de camping que abrigam em épocas festivas mais turistas do que o suportado, entre outros.

O crescimento da atividade do ecoturismo e a crescente expansão imobiliária são termômetros que mensuram a celeridade das transformações por que passa a região. Uma parcela crescente da população metropolitana busca a fuga do cotidiano urbano e o reencontro com a natureza, expressada pelo ...eio físico. Este processo movimenta e acumula rendas e problemas, mesmo em regiões aparentemente distantes de um cotidiano mais associado à vida urbana. Qualquer distrito, por menor que seja, produz e reproduz processos sócio-espaciais, que se materializam ao longo do tempo. Para compreender esses processos e os conflitos inerentes na formação do "tecido urbano" é necessário desvendar os modos historicamente construídos, como propõe Oliveira (1977: 67) o "espelho urbano se estilhaça em mil partes que reflete em cada um de seus mil pedaços a mesma imagem". Cardeal Mota é mais um deles.

\section{A Geo-História de Santana do Riacho}

Para compreender essa (re)produção do espaço urbano e os problemas sócioambientais hoje presentes em Cardeal Mota foi necessário resgatar as referências histórico-geográficas deixadas na localidade, conforme propõe Gonçalves (1995:311). Neste caso chega-se à intercessão dos dois "vetores histórico-geográficos" mencionados, o rio Cipó e as trilhas que se dirigiam para o Arraial do Tejuco (atual Diamantina), caracterizando um significativo problema urbano, a questão fundiária.

O processo de produção do espaço urbano de Santana do Riacho tem suas origens a partir da colonização portuguesa no século XVIII, sendo que parte do município pertenceu à comarca de Serro Frio, na freguesia de Conceição do Mato Dentro. Foi ao longo das trilhas deixadas pelos bandeirantes, que surgiram os primeiros povoados. Algumas localidades constituíram-se justamente com a dificuldade de transposição dos cursos d'água, o povoado de Riacho Fundo (antiga denominação de Santana do Riacho), atual sede municipal, a primeira a surgir, seguida tempos depois pelo povoado da Serra da Vacaria, que abriga o distrito de Cardeal Mota, quando os tropeiros atravessavam o próprio rio Cipó.

O primeiro colonizador da região, o Sargento-mor Antônio Ferreira de Aguiar de Sá, recebeu as terras da coroa portuguesa através de uma sesmaria (1759). Até a promulgação da Lei de Terras a formação do latifúndio era fácil, as terras eram simplesmente doadas às elites. É justamente a formação destes latifúndios que dá origem à questão fundiária, cujo enfrentamento vem se arrastando durante esses anos. 
Apesar de não ter um solo propício para lavoura extensiva, percebe-se que a formação do latifúndio associava-se ao processo de exploração do meio físico, vislumbrando-o como um recurso natural inesgotável. As primeiras conseqüências ambientais desta exploração foram denunciadas pelo naturalista Saint-Hilaire (1816), ao referir-se ao processo de mineração e supressão da vegetação. Com o advento da Lei de Terras (1850) a propriedade rural passou a ter mais valor econômico, portanto significava mais poder, acirrando-se as brigas entre as autoridades locais. No século XIX a fragilidade da questão é tamanha, que o próprio Estado interfere, por diversas vezes, nos limites territoriais do povoado de Riacho Fundo, um verdadeiro rosário de leis foi editado. Santana do Riacho consagra-se como município emancipado somente em 1962 e junto é delimitado seu único distrito, Cardeal Mota. De sua emancipação até a instalação das unidades de conservação, na década de 80, Santana do Riacho preservou praticamente o mesmo perfil municipal, era uma ilha que gravitava no entorno da região metropolitana de Belo Horizonte, mas a questão fundiária permanece latente.

\section{As Unidades de Conservação}

As criações dessas áreas protegidas alavanca, paradoxalmente, o crescimento da urbanização e os conflitos sócio-ambientais. A proposta do Estado era justamente "preservar" o ambiente natural, mas ele fomenta "novamente" uma questão "velha": a briga pela terra, seja pelos processos de desapropriação ocorridos para constituir o Parque, seja pela valoração do preço da terra na região do entorno, que está dentro da área de proteção ambiental. O Estado, através do IBAMA, busca equacionar o problema fundiário, indenizando as pessoas que moravam dentro da área do atual parque, mas a burocracia estatal, aliada à falta de titulação da propriedade da terra, alimenta a lentidão do processo, que se arrastou durante quase vinte anos. No lado externo do parque, as terras são disputadas pelo mercado imobiliário e a regulação ambiental mostra-se incapaz de uma postura reativa. Essa valorização da terra desperta a atração de mais pessoas para a localidade, especialmente ecoturistas e sitiantes (a fugir da vida citadina), acelerando o processo de urbanização, principalmente em Cardeal Mota.

O espaço urbano de Santana do Riacho-Cardeal Mota é resultado de um processo de articulações de interesses entre governo local e os empresários do setor imobiliário. As disputas dos empresários locais pelas terras de loteamentos são acirradas e expressam mais uma vez a questão fundiária em aberto, desde o período colonial. Apesar ser possível identificar todas pessoas envolvidas nessa dinâmica, a localidade prefere deixá-las anônimas (invisíveis), não há uma mobilização social contra esse tipo de empreendimento, pois parte dessas pessoas têm estreita ligação com a própria (re)produção do espaço, seja possuindo um "pedacinho de terra", ou tendo parentes ou amigos que conseguiram comprá-las ou a exploram de alguma forma. 


\section{A mobilização em torno da estrada: a Audiência Pública}

Recentemente, a comunidade de Cardeal Mota vivenciou um interessante processo de mobilização que culminou em audiência pública para discussão de obras viárias envolvendo a pavimentação da MG-10, principal via de acesso ao distrito, que dentro de sua área urbana superpõe-se à rua principal. $\mathrm{O}$ processo mobilizou várias entidades comunitárias locais, os órgãos públicos ambientais (FEAM, IBAMA), o DER-MG responsável pela obras, e Ministério Público Federal. A polêmica teve origem na concessão, em 1996 pelo COPAM, de "Licença de Instalação" para as obras, onde eram determinados condicionantes visando minimizar o impacto ambiental, dentre eles a revitalização do patrimônio histórico, cultural e paisagístico da Serra do Cipó, além de melhorias urbanísticas no trecho do povoado de Cardeal Mota cortado pela rodovia, dada a vizinhança do Parque Nacional da Serra do Cipó e por estar dentro da APA Morro da Pedreira. No entanto as determinações do processo de licenciamento não estavam sendo cumpridas pelo DER, já que este produziu apenas um projeto convencional de engenharia rodoviária, e crsciam preocupações com os prováveis impactos negativos decorrentes do aumento significativo do fluxo de veículos, inclusive de carga, se sérias medidas não fossem tomadas. Assim, conforme registra o material de divulgação da audiência, "a comunidade reconhece a importância das obras da estrada, na medida em que se integram importantes circuitos turísticos, como o do Ouro, das Grutas, da Serra do Cipó e do Diamante. Entretanto, reivindica ao DER o compromisso de garantir as condicionantes ambientais asseguradas por lei, bem como a dignidade de um empreendimento de tamanha relevância para o estado de Minas Gerais".

Invocando o exercício da cidadania, o evento foi bastante concorrido, com mais de 300 pessoas e um expressivo leque de apoios de instituições, entidades, profissionais e moradores. Os resultados estão ainda sendo construídos, seja na forma de propostas alternativas e mais condizentes com a realidade local, de traçado da rodovia, bem como na negociação das famosas "medidas compensatórias". Assim é que como resultado direto da mobilização, houve uma decisão pela reformulação do projeto da estrada, para a qual já houve inclusive garantia de alocação dos recursos necessários, em reunião do COPAM. É interessante observar que o tema foi capaz de aglutinar uma parcela considerável da representação da comunidade, já que a ameaça era bastante perceptível e o interlocutor também muito bem definido, na forma do DER e seu projeto. Outras transformações, como o contínuo parcelamento do solo, as mudanças de valores e de hábitos em função do turismo crescente, entre outras, parecem produzir respostas mais ambíguas, até porque os interesses são mais difusos e não podem a priori ser identificados apenas como uma "ameaça externa".

Outro aspecto a ser discutido refere-se à concepção dominante e à eficácia dos instrumentos de avaliação e planejamento ambiental, como os EIA-RIMA, enquanto capazes de produzir uma análise de qualidade para situações concretas. Neste caso em particular, o RIMA elaborado e apresentado publicamente na audiência restrin- 
gia-se aos impactos imediatos do funcionamento da estrada, adotando uma visão convencional de meio ambiente. Os chamados "impactos antrópicos" ficavam muito aquém da compreensão do conjunto de transformações que vêm se operando na região, e que provavelmente serão magnificados pelo asfaltamento da estrada após a localidade. Do ponto de vista da avaliação do instrumento, trata-se de um velho dilema, já presente desde os primeiros planos diretores da década de setenta, segundo o qual a obrigatoriedade de um diagnóstico, um plano ou uma avaliação, ainda que bem intencionados, não são necessariamente garantia de qualidade. Por outro lado, há que ressaltar uma importante diferença. A legislação ambiental, ao prever instâncias onde é possível a participação dos envolvidos, permite algumas correções de rumos, como parece sugerir este caso. Os desdobramentos e suas consequiências, entretanto, ainda estão por acontecer.

Desenvolvimento sustentável é um termo aparentemente consensual e apropriado por diversos discursos ambientalistas, desde o final da década de 70, fazendo com que sofresse deturpações conceituais. Já o conceito de justiça ambiental, citado por HARVEY (1997), procura associar, politicamente, sociedade e meio ambiente, apontando que a causa real dos problemas ambientais pode ser encontrada nas relações sociais. $\mathrm{O}$ problema central nos remete às formas de acumulação de capital e à assimetria entre poder político e econômico.

Como qualquer outra norma, a legislação ambiental ou urbana, também busca proteger as pessoas (físicas ou jurídicas) nas suas relações sociais. Considerando-se que o bem tutelado é o meio ambiente, ou seja, aquilo que está ao redor, inclusive a propriedade alheia ou até mesmo as edificações de uma cidade, usufruímos indiretamente desses bens ambientais; além de termos obviamente a possibilidade de interagir diretamente. Mas para que a premissa constitucional realmente aconteça, que todos tnham acesso ao meio ambiente ecologicamente equilibrado, é necessário que as pessoas usufruam diretamente desse bem (que é de sua propriedade), mas considerem que as demais pessoas também têm o direito de acessá-lo indiretamente, estando protegidas pelos interesses difusos. O livre arbítrio com relação à propriedade deve ser pautado por essas normas, para que outros (principalmente aqueles que não tem propriedade e acesso direto a esses bens), não tenham seus direitos afetados.

Para o capital investido (principalmente o imobiliário), naturalmente, o importante é o sucesso do empreendimento, materializado na venda de lotes ou receber mais turistas, sendo irrelevantes questões como acesso à terra; o comprador de lotes vislumbra o refúgio, a construção de sua segunda casa, nem sempre pautada pelo respeito às características ambientais do terreno; o poder local busca administrar o precário equilíbrio entre a necessidade de satisfazer os eleitores que desejam ver o crescimento local (principalmente o econômico) e os desafios da preservação e atendimento às regulações urbanísticas e ambientais; as agências estatais usualmente agem "apagando incêndio" a partir de denúncias individuais ou coletivas. Planejamento participativo com a população envolvida ou tarefas pró-ativas não são pratica corrente; basta relembrar que APA Morro da Pedreira até o momento não logrou 
êxito em seu processo de gestão, além da Lei Orgânica Municipal prever um Plano Diretor que ainda não foi sequer iniciado.

Diante de tudo isso, pode-se questionar o legado que está sendo deixado para as gerações futuras. Até que ponto a educação ambiental, por exemplo, estaria sendo desenvolvida para as crianças e as demais pessoas que freqüentam a região, buscando aguçar esse senso crítico, corroborando noções de ética e respeito aos bens ambientais.

A experiência da Serra do Cipó expõe a clara articulação entre a questão ambiental e a questão urbana. Fica porém evidente nas falas das pessoas que a questão ambiental é bem aceita pela sociedade e amplamente presente nos discurso. Há mais apelo em se levantar uma bandeira pelo "meio ambiente" do que pelo "urbano". Em Santana do Riacho ficou explicito a vulnerabilidade das instituições públicas para lidar com o problema urbano. Apesar da gestão compartilhada, com participação popular, necessitar de muitos aperfeiçoamentos (inclusive em termos de sua real implantação em Santana do Riacho), constitui ainda um caminho possível de mudança social e de reparação das fragilidades das instituições locais, especialmente o CODEMA.

Segundo caso: Porto Seguro e os impactos sócio-ambientais do turismo de massa no litoral brasileiro

Algumas observações sobre a noção de Urbanização Turística

O Nordeste do Brasil, com sua extensa faixa litorânea, vem sendo nesta última década, alvo de pesquisas relacionadas a turismo, impactos ambientais e urbanização, o que vem alimentando o debate acerca de novos processos de transformação do espaço, sobretudo dos espaços que servem à demanda do turismo. Mullins (1991 ${ }^{11}$, apud SILVA, 1997: 166) utiliza noção de urbanização turística para associar a dinâmica de funcionamento do turismo ao processo de urbanização. Assim, “...os centros turísticos são uma nova e extraordinária forma de urbanização porque são cidades construídas unicamente para o consumo" e ainda que nesta forma de urbanização "cidades e vilas (são) construidas explicitamente para o prazer". O exemplo mais comumemte utilizado é Cancún, localizada na ponta da península de Yucatan, no México, uma cidade que foi erigida pelo turismo e para o seu consumo.

"Em cerca de duas décadas, uma praia praticamente selvagem, localizada na periferia da economia mexicana, transformou-se no segundo ponto de maior afluência do turismo global, depois de Orlando, Disney World" (BARROS, 1994).

\footnotetext{
${ }^{10}$ Ver Ramos (2002) para uma discussão aprofundada deste caso.

${ }^{11}$ Mullins, Patrick. Tourism urbanization. International Journal of Urban and Regional Research, 15(3), 1991.
} 
Há certamente na literatura um crescente debate acerca do turismo como vetor de desenvolvimento, particularmente como alternativa econômica de caráter local. Para alguns, trata-se de um novo fenômeno social capaz de processar grandes interferências nos meios onde ocorre, particularmente no processo de produção do espaço.

Para Luchiari a urbanização turística pode ser entendida como uma nova organização sócio-espacial originada da junção entre velhos e novos espaços:

"Este movimento entre o velho e novo, acelerado pela urbanização turística, gera novas paisagens, consome outras, traz à cena novos sujeitos sociais, elimina ou marginaliza outros e redesenha as formas de apropriação do espaço urbano, substituindo antigos usos e elegendo novas paisagens a serem valorizadas pelo prazer." (LUCHIARI, 1998:17)

Ao focalizar a urbanização turística no caso da cidade de Natal (RN), Lopes Júnior (LOPES JUNIOR, 2000:213) destaca que

"o conceito de urbanização turística tem emergido nos últimos anos para expressar uma nova forma derivada da conexão entre o desenvolvimento de atividades turísticas e a emergência de novas paisagens urbanas no fim do século XX."

\section{Porém o autor afirma que}

"em Natal, a urbanização turística não chega a moldar toda a cidade nem a redefinir completamente sua vida econômica."

Uma outra concepção é dada por Cruz, ao ressaltar a idéia de urbanização para o turismo, argumentando que:

"embora a urbanização turística seja uma forma de urbanização para o turismo, a distinção conceitual se faz necessária porque, em se tratando do litoral nordestino, há casos em que o processo de apropriação do espaço pelo turismo não chega a ser uma urbanização turística."(CRUZ, 2000:142)

A distinção proposta por Cruz aplica-se ao exemplo de Porto Seguro, pois além dos espaços produzidos unicamente para o uso turístico (praias, praças, centros comerciais etc.), considera-se o conjunto das transformações sócio-espaciais englobando outras áreas que não aquelas de uso exclusivo do turismo (as periferias urbanas, as áreas socialmente excluídas, etc.). Assim, o turismo enquanto atividade econômica, redefiniu a dinâmica demográfica regional, "moldando" o espaço urbano e consumindo vorazmente, de forma literal e figurada, o patrimônio ambiental local.

Do ponto de vista da relação entre população e meio ambiente nos espaços em processo de acelerada transformação gerada pelo turismo, permanece atual a argumentação de Martine, segundo a qual

“ (...) a forma de a questão demográfica incidir sobre o problema ambiental no Brasil está mais relacionada com a utilização do espaço do que com o crescimento vegetativo. O que têm a ver os padrões de distribuição da população com a questão ambiental? Ocorre que a redistribuição da população sobre o espaço obedece à evolução da localização e da reestruturação da atividade econômica. " (MARTINE, 1996:31)

\footnotetext{
${ }^{12}$ Há uma produção acadêmica crescente envolvendo os temas urbanização, impactos ambientais e turismo, fortemente centrada em estudos de caso. Segundo Rejowski (1997), detectou-se no âmbito da geografia, a maior produção sobre o tema turismo, no período que antecede aos anos 90 , continuando a ser significativa desde então.
} 
Os conflitos de uso do espaço desencadeados pelo turismo se enquadram nesta discussão, quando as estratégias e políticas de desenvolvimento local, inclusive de incentivo à migração são implementadas num processo alheio a qualquer tipo de planejamento ou avaliação de riscos.

\section{Urbanização e impactos sócio-ambientais em Porto Seguro}

Já amplamente reconhecido como sendo uma atividade que gera altas divisas, o turismo tem de forma direta e indireta, fomentado diferentes processos de transformações nas áreas urbanas onde se desenvolve. São particularmente importantes questões ligadas ao crescimento sazonal da população, à exploração intensiva de recursos naturais, inclusive do recurso terra por meio de intensa atividade imobiliária, ao risco de esgotamento do patrimônio cultural e ambiental, às condições de reprodução e trabalho da população residente, esta também oriunda de intensos processos migratórios desencadeados pelas possibilidades de inserção oferecidas pelo turismo, entre outras tantas que afligem a população residente nas cidades turísticas a beira-mar.

Porto Seguro, localizada no Extremo-Sul da Bahia, é na atualidade um dos mais importantes roteiros turísticos litorâneos em escala local e regional. O tipo de turismo que ocorre em Porto Seguro, caracteriza-se pelo uso dos diferentes espaços geográficos, desde os "naturais", até aqueles que foram criados e são continuamente reestruturados para atendimento ao fluxo turístico que ocorre durante todo o ano. Além da chamada alta estação nos primeiros meses do ano, verifica-se uma visitação durante todos os demais períodos, estimulada sobretudo pela infra-estrutura composta pelos atrativos artificiais, tais como um amplo setor de serviços, comércio e espaços especializados em diversão e entretenimento.

A evolução da população urbana nos distritos do município de Porto Seguro evidencia o acelerado crescimento demográfico das últimas décadas, período de implantação da atividade turística, inicialmente na forma de um turismo "alternativo" nos anos setenta, para consolidar-se como turismo de massa, iniciado a partir dos anos oitenta e principalmente na década de noventa. Assim, a cidade de Porto Seguro com seus aproximadamente 5.000 habitantes do início de 1980 salta para os quase 70.000 habitantes em 2000 .

\section{População Urbana dos Distritos - Município de Porto Seguro}

1980,1991 e 2000

\begin{tabular}{cccc}
\hline Distrito & 1980 & 1991 & 2000 \\
\hline Arraial D'Ajuda & - & - & 10.019 \\
\hline Caraíva & 270 & 1.954 & 438 \\
\hline Porto Seguro & 5.000 & 16.611 & 64.171 \\
\hline Trancoso & - & - & 4.538 \\
\hline Vale Verde & 472 & 4.736 & 391 \\
\hline
\end{tabular}

Fonte: FIBGE, Censos Demográficos 1980, 1991 e 2000. 
Esta mudança não se expressou apenas na dinâmica demográfica, mas também na estrutura do espaço urbano. A malha urbana se ampliou e a cidade, antes uma pacata vila de pescadores, experimentou um processo progressivo de expansão urbana resultando em áreas degradadas, seja pelas ocupações na forma de favelas em meio à área de manguezal com forte impacto para o ecossistema local, seja pelo surgimento de novos bairros com um elevado contingente populacional, desprovidos das condições mais elementares de infra-estrutura urbana, a exemplo de serviços de saneamento básico ou ainda pelo ininterrupto parcelamento da orlà marítima para residências de veraneio, feito em condições de completo descaso à vegetação nativa e às condições de saneamento ambiental, acrescentando com crescente frequência longas faixas negras às águas azuis que caracterizam a paisagem litorânea local.

Os investimentos em infra-estrutura, como é típico de nossa urbanização incompleta, não se estenderam igualmente a todos os espaços da cidade e alguns dos novos espaços incorporados à cidade, particularmente aqueles formados a partir de intensos fluxos migratórios regionais estimulados pelo boom do turismo, passaram a ser caracterizados como um espaço à margem da Porto Seguro turística, a que denominamos a outra face da urbanização turística (COSTA e RAMOS, 2001). São extensas áreas de expansão urbana, formadas por um conjunto de loteamentos, originalmente implantados para abrigar expressivos contingentes migratórios regionais atraídos pelo trabalho no turismo. Atualmente, pode-se dizer que tais áreas, conhecidas como "Baianão", pouco se diferenciam das periferias carentes das aglomerações urbanas, responsáveis por expressivas parcelas do crescimento urbano da última década. Entretanto, sintomaticamente, as áreas urbanas compreendidas pelo "Baianão" permanecem quase invisíveis ao turista, por sua localização estratégica na direção contrária ao valorizado litoral, "do outro lado da rodovia" e do aeroporto, "protegidas" por outdoors e alguma vegetação.

É possível identificar o rápido crescimento do setor serviços devido ao desenvolvimento do turismo, como decorrência do um contínuo fluxo de migrações para a cidade de Porto Seguro, estimuladas, tanto pelo atrativo exercido pelo novo mercado de trabalho onde a qualificação e experiência não eram pressupostos básicos, quanto

\section{Empresas fundadas entre 1980 e 1996 Porto Seguro}

\begin{tabular}{cc}
\hline Ano & Total de Empresas \\
\hline 1980 a 1984 & 23 unidades \\
\hline 1985 a 1989 & 189 unidades \\
\hline 1990 a 1994 & 709 unidades \\
\hline 1995 em diante & 562 unidades \\
\hline Total em 1996 & 1483 unidades \\
\hline
\end{tabular}

Fonte: IBGE, 1996.

Nota: Empresas atuando nos setores de hotelaria, suporte ao turismo, lazer, entre outros, distribuídas em toda extensão do litoral de Porto Seguro e não apenas na Sede Municipal. 
pela influência direta e indireta do poder público municipal que estimulava a entrada de significativas levas de migrantes, inclusive pelo oferecimento de lotes. O quadro a seguir apresenta uma aproximação da expansão do setor..

Quanto à origem, a migração para Porto Seguro caracteriza-se principalmente por seu caráter regional, como bem o ilustra o quadro a seguir.

Origem dos Migrantes

\begin{tabular}{ccc}
\hline Lugar de origem & Valor absoluto & Valor Relativo (\%) \\
\hline Estado da Bahia & 16.598 & 83.6 \\
\hline Outros Estados & 3.145 & 15.8 \\
\hline Outros Países & 114 & 0.6 \\
\hline Total & 19.857 & 100.0 \\
\hline
\end{tabular}

Fonte: www.ibge.gov.br, 1996.

Os dados do quadro referem-se às pessoas que não residiam no município até 01.09.1991. Sabe-se, porém que o processo continuou de forma bastante intensa. $\mathrm{O}$ princípio dos anos 90 foi determinante para o crescimento populacional de Porto Seguro e, consequentemente, para a ampliação do processo de urbanização. Ao passo que crescia a atividade turística, cresciam também os problemas sócio-ambientais. Neste contexto destaca-se a continuidade da ocupação de áreas de risco (fundo de vales, encostas), o contínuo desmatamento e a destruição de áreas remanescentes de Mata Atlântica, o aumento da produção de resíduos sólidos, entre outros problemas ambientais.

Um dos indicadores dos impactos ambientais do turismo de massa litorâneo refere-se às usualmente precárias condições de saneamento básico, associadas à incapacidade das estruturas administrativas locais de lidar com a crescente demanda, como apontam os dados do quadro abaixo.

\section{População Litorânea no Brasil e volume de esgotos produzidos} 1970 a 1996

Ano População litorânea Casas de Veraneio Esgoto Produzido (l por hora)

\begin{tabular}{llcl}
\hline 1970 & 20 milhões & $*$ & 125 milhões \\
\hline 1980 & 26 milhões & 350.000 & 162 milhões \\
\hline 1991 & 32 milhões & $*$ & 200 milhões \\
\hline 1996 & 36 milhões & 562.000 & 225 milhões \\
\hline
\end{tabular}

Fonte: FIBGE e Associação Brasileira de Engenharia Sanitária. In: Revista Veja, 20 de janeiro de 1999

* dados não disponíveis 
Aos problemas mais diretamente ligados à esfera do meio ambiente, associam-se os de ordem sócio-econômica, determinados pela má distribuição da renda e dos benefícios econômicos advindos do desenvolvimento turístico. As condições de trabalho e os salários pagos são marcados também pela disparidade, tanto no que se refere à qualificação, quanto aos rendimentos obtidos pelo trabalhador.

Pelos indicadores apresentados a seguir, observa-se que a atividade turística colocou Porto Seguro em posição de destaque no cenário baiano, permitindo-o figurar entre os 10 primeiros municípios com maior arrecadação dentre os mais de 400 existentes no Estado da Bahia, perdendo apenas para regiões onde destacam-se atividades ligadas ao refino e distribuição de petróleo e seus derivados. Este quadro contrasta com a colocação de Porto Seguro no que tange aos índices de desenvolvimento social, sugerindo que os recursos do turismo não têm tido o correspondente retorno social e colocando em cheque a tão difundida visão da atividade como uma fonte segura de desenvolvimento local.

\section{Municípios Baianos selecionados, classificados segundo Receitas Tributárias, Índice de Desenvolvimento Social e Índice de Desenvolvimento Econômico 1996}

\begin{tabular}{cccc}
\hline Município & $\begin{array}{c}\text { Class. por Receita } \\
\text { Tributária }\end{array}$ & Class. por IDS & Class. por IDE \\
\hline São Francisco do Conde & $1^{\circ}$ & $18^{\circ}$ & $3^{\circ}$ \\
\hline Camaçarí & $2^{\circ}$ & $31^{\circ}$ & $2^{\circ}$ \\
\hline Salvador & $3^{\circ}$ & $1^{\circ}$ & $1^{\circ}$ \\
\hline Lauro de Freitas & $4^{\circ}$ & $13^{\circ}$ & $9^{\circ}$ \\
\hline Madre de Deus & $5^{\circ}$ & $9^{\circ}$ & $153^{\circ}$ \\
\hline Dias D'Avila & $6^{\circ}$ & $3^{\circ}$ & $14^{\circ}$ \\
\hline Porto Seguro & $7^{\circ}$ & $165^{\circ}$ & $17^{\circ}$ \\
\hline
\end{tabular}

Fonte: SEL/Informações Básicas dos Municípios - www.sei.ba.gov.br

Obs.: Em São Francisco do Conde localiza-se a refinaria de petróleo Landulfo Alves, a única do Nordeste.

A urbanização centrada nas possíveis vantagens oferecidas pelo turismo, fez de Porto Seguro um dos mais significativos exemplos de crescimento urbano, em termos demográficos e espaciais, associados à consolidação de um determinado tipo de turismo, o turismo litorâneo de massa. As elevadas taxas de crescimento, naturalmente referem-se à população permanente e variam na mesma proporção em que se dá o boom turístico. Tal crescimento, argumentamos, deve ser compreendido em

\footnotetext{
${ }^{13} \mathrm{Na}$ composição das Receitas Tributárias, destacam-se o IPTU, o ISS, entre outros impostos e taxas. O Índice de Desenvolvimento Social (IDS) inclui as seguintes variáveis: saúde, educação, serviços básicos e renda média dos chefes de família. Já o Índice de Desenvolvimento Econômico (IDE) é formado por variáveis associadas a infraestrutura, qualidade da mão-de-obra e produto municipal.
} 
termos demográficos como aquele que absorve uma nova população que dependente do turismo como principal fonte de renda e sobrevivência. A ela deve-se acrescer o afluxo temporário, porém existente durante todo o ano, dos visitantes. Visto sob a ótica espacial, o crescimento urbano corresponde a espaços distintos, um representado pelo uso e apropriação para o turismo e outro, sua face oculta, para simples reprodução da força de trabalho. (Ramos, 2002).

\section{Taxas de Crescimento Anual Médio \\ População Urbana \\ 1980 - 2000}

\begin{tabular}{cccc}
\hline UNIDADE & $1980 / 1991$ & $1991 / 2000$ & $1980 / 2000$ \\
\hline Brasil & 2,80 & 2,41 & 2,62 \\
\hline Bahia & 3,62 & 2,51 & 3,12 \\
\hline Porto Seguro & 13,57 & 14,61 & 14,04 \\
\hline
\end{tabular}

Fonte: FIBGE - Censos Demográficos - 1980, 1991 e 2000.

A urbanização associada ao turismo, com seus sérios conflitos de uso e apropriação do espaço e crescente consumo destrutivo do patrimônio ambiental e cultural da região, coloca em questão a própria sustentabilidade da atividade. Este conjunto de conflitos sócio-ambientais, no qual a população tem papel determinante, consolida um quadro de crise agravado pela falta de planejamento urbano municipal, de políticas voltadas ao desenvolvimento social em diferentes níveis, local, regional e nacional, bem como pela ausência de formas mais democráticas de definição de prioridades a nível local. Neste sentido Porto Seguro é o retrato da produção do espaço subordinada a grandes interesses econômicos que certamente possibilitam a inserção da população, porém às custas de elevados riscos sociais e ambientais. Este eterno dilema, tradicionalmente presente em áreas industriais e poluídas, reaparece na sedutora pele de cordeiro do turismo litorâneo. A forte pressão ambiental, neste caso, é exercida não apenas pelos visitantes que consomem vorazmente espaço, cultura e lazer, mas também e sobretudo pela população residente, que se apropria deste espaço da forma que pode, reproduzindo práticas aparentemente justificáveis exclusivamente pela ilusão do retorno econômico prometido por esta forma particular de turismo de massa.

\section{Considerações Finais}

Os casos brevemente discutidos, embora fundamentalmente diferentes em sua dinâmica e nas relações sociais, evidenciam profundos processos de transformação ambiental e na estrutura social das regiões, tendo a atividade do turismo como elemento motor. Entretanto, questões ligadas aos processos imobiliários e fundiários 
estão presentes nos dois casos, com as devidas especificidades. Do ponto de vista das possibilidades de gestão urbano-ambiental, diferenças significativas separam os dois casos.

Na região da Serra do Cipó, possivelmente por sua proximidade à Região Metropolitana de Belo Horizonte, bem como pela importância do patrimônio natural, o crescente turismo ecológico dificilmente se expandirá para um turismo empresarial de massa nos moldes de Porto Seguro. Entretanto a gestão do Parque Nacional, e da APA que o circunda, incluindo-se os (ainda) pequenos núcleos urbanos tradicionais deve necessariamente considerar a natureza das transformações por usos ligados ao turismo, assim como pelo crescente número de parcelamentos destinados a sítios de recreio e segundas residências. A natureza contraditória do impacto das atividades turísticas e do processo de urbanização por elas desencadeado é um importante elemento na compreensão dos conflitos existentes, sejam eles latentes ou explicitados.

No segundo caso, como consequência de um conjunto de investimentos públicos e privados que transformaram a região num dos principais pólos turísticos do estado e do país, não se trata de discutir as possibilidades de mediação via processos de gestão compartilhada, mas de avaliar algumas das muitas implicações sócioambientais de um processo orquestrado de produção do espaço para o turismo, particularmente o turismo de massa. Isto é, contraposição da urbanização turística, diretamente associada a processos de produção do espaço de/para o consumo e o lazer, à sua irmã gêmea e antítese: a urbanização que abriga os trabalhadores, migrantes atraídos pelas possibilidades de trabalho originadas pelo turismo, revelou algumas das distorções espaciais das transformações discutidas.

Ao abordar situações que ainda estão em construção, como é o caso da gestão de APAs, a discussão proposta neste trabalho, naturalmente, ganha em atualidade, mas perde por impossibilidade de manter o necessário distanciamento da realidade. Em alguns casos, a pesquisa acontece quase simultaneamente aos fatos e situações por ela analisados. Este certamente é o caso do conflito existente hoje na Serra do Cipó. Com isto, as curiosidade pelos desdobramentos e implicações das situações, por si só, já apontam novos caminhos para a pesquisa. Entretanto, os exemplos escolhidos demonstram que processos de gestão compartilhada, participação popular, ou instâncias colegiadas de deliberação, embora ainda necessitem de muitos aperfeiçoamentos, constituem caminhos possíveis de mudança social, logo formas coletivas de construção do futuro. Os exemplos apontam simultaneamente para a força das idéias e a vulnerabilidade das instituições que as viabilizam como políticas públicas. Assim, é no sentido da eliminação das fragilidades e fortalecimento da gestão coletiva e transformadora que futuras pesquisas envolvendo população, gestão e meio ambiente deverão apontar.

POPULAÇÃO, TURISMO E URBANIZAÇÃO: CONFLITO NO USO E GESTÃO AMBIENTAL 
Resumo: O turismo urbano é um tema em franco desenvolvimento, como prática social e como pesquisa universitária. O texto compara e analisa o turismo urbano em Minas Gerais e na Bahia.

Palavras-chave: Cidade, Turismo, Meio Ambiente

POPULATION, TOURISM AND URBANIZATION: CONFLICT IN THE USE AND ENVIRONMENTAL MANAGEMENT

Abstratct: Urban tourism is a theme in frank development so a social practice as university researches. This text compares and analyzes urban tourism in Minas Gerais and Bahia.

Key words: City/ Tourism, Environment.

\section{BIBLIOGRAFIA}

BRASIL. 1981. Lei n ${ }^{\circ} 6.938$ de 31 de agosto de 1981. Dispõe sobre a Política Nacional do Meio Ambiente, seus fins e mecanismos de formulação e aplicação, e dá outras providências. Brasília: Câmara dos Deputados.

Resolução $n^{\circ} 01$ do Conselho Nacional de Meio Ambiente - CONAMA, de 23 de janeiro de 1986. 1986. Dispõe sobre a implementação de Avaliação de Impacto Ambiental e dá outras providências. Brasília: Câmara dos Deputados.

CAMARGOS, Regina M. F. 2001. Reservas naturais do Brasil: a transição dos conceitos. Belo Horizonte: IGC/UFMG. (Dissertação, Mestrado em Geografia)

CAMARGOS, Regina M.F. 2001. Unidades de Conservação em Minas Gerais: levantamento e discussão. Belo Horizonte: Fundação Biodiversitas.

COSTA, Heloisa S.M. 2001. Tendências recentes de produção do meio ambiente urbano: planejamento, conflito e gestão urbano-ambiental. Belo Horizonte: IGC/ UFMG. (Relatório de Pesquisa, CNPq).

COSTA, Heloisa.S.M.; RAMOS, Marcelo V. 2001. The hidden face of touristic urbanisation. In: XXIV GENERAL POPULATION CONFERENCE, 2001, Salvador. Proceeding... Paris: IUSSP. (disponível em CD-Rom).

CRUZ, Rita de C. 2000. Política de turismo e território. São Paulo: Contexto.

GONÇALVES, Carlos Walter Porto. 1995. Formação sócio-espacial e questão ambiental. In: BECKER, B. et al, Geografia e Meio Ambiente no Brasil. São Paulo: Editora HUCITEC. p.309-333.

HARVEY, David. 1997. Justice, nature and the geography of difference. Blackwell Publishers.

INSTITUTO BRASILEIRO DE GEOGRAFIA E ESTATÍSTICA - IBGE. Censo Demográfico de Minas Gerais de 2000. Série Regional. Rio de Janeiro, 2001.

KOWARICK, Lúcio. 2000. Escritos urbanos. São Paulo: Editora 34.

LEFEBVRE, Henri. 1999. A Revolução Urbana. Trad. Sérgio Martins. Belo Horizonte: Editora UFMG. 178p. (Tradução de: La Revolution Urbaine).

LOPES JUNIOR, Edmilson. 2000. População e meio ambiente nas paisagens da urbanização do Nordeste: o caso de Natal. In: TORRES, Haroldo; COSTA, Heloisa. (orgs.) 2000. População e meio ambiente; Debates e desafios. São Paulo: Ed. SENAC. 
LUCHIARI, Maria Tereza. 1998. Urbanização turística, um novo nexo entre o lugar e o mundo. In: CRUZ, Luiz (org.). Da cidade ao campo: a diversidade do saber fazer turístico. Fortaleza: UECE.

MARTINE, George. 1996. População, Meio Ambiente e Desenvolvimento : o cenário global e nacional. In: MARTINE, G. (org.) População, meio ambiente e desenvolvimento; Verdades e contradições. Campinas, SP: UNICAMP. (2a. ed.)

MINAS GERAIS. 1980. Lei ${ }^{\circ} 7.772$ de 08 de setembro de 1980. Dispõe sobre proteção, conservação e melhoria do meio ambiente, e.dá outras providências. Minas Gerais: Assembléia Legislativa.

OLIVEIRA, Alexandre M. 2002. A preservação ambiental e a urbanização na Serra do Cipó. Belo Horizonte: IGC/UFMG (Dissertação de Mestrado em Geografia) OLIVEIRA, Francisco de. 1977. Acumulação Monopolista, Estado e Urbanização: A Nova Qualidade do Conflito de Classes. In: MOISÉS, J.A. et alli (org.). Contradições Urbanas e Movimentos Sociais. Rio de Janeiro: Editora Paz e Terra. p.65-76.

OLIVEIRA, Sônia. 2001. Conflitos ambientais e lutas simbólicas. In: X ENCONTRO NACIONAL DA ASSOCIAÇÃO NACIONAL DE PÓS-GRADUAÇÃO E PESQUISA EM PLANEJAMENTO URBANO E REGIONAL, 2001, Rio de Janeiro. Ética, planejamento e construção democrática do espaço. Anais... Rio de Janeiro: ANPUR. p.1311 - 1321.

RAMOS, Marcelo V. 2002. Impactos sócio-ambientais do turismo: a produção do espaço urbano em Porto Seguro. Belo Horizonte: IGC/UFMG. (Dissertação de Mestrado em Geografia)

SILVA, Silvio B.M. 1997. Turismo e urbanização. In: RODRIGUES, A.B. (org.). Turismo, modernidade e globalização. São Paulo: HUCITEC. 